\title{
Gestión de colecciones fotográficas: Proyecto Infoco para la creación de un censo- guía de fondos y colecciones fotográficas en España, Portugal e Iberoamérica
}

Management of photographic collections: The Infoco Project for the creation of a census of photography collections in Spain, Portugal and Latin America

\author{
María Olivera Zaldua (1), Juan Miguel SÁnchez Vigil (2), Juan Carlos Marcos Recio (3)
}

(1) Departamento de Biblioteconomía y Documentación, Facultad de Documentación de la Universidad Complutense de Madrid, C/ Santísima Trinidad, 37, 28010 Madrid-España, molivera@pdi.ucm.es (2) jmvigil@ccinf.ucm.es (3) Sección Departamental de Biblioteconomía y Documentación, Facultad de Ciencias de la Información de la Universidad Complutense de Madrid, Av. Ciudad Universitaria s/n, 28040 Madrid (España), jmarcos@ccinf.ucm.es

\begin{abstract}
Resumen
La gestión de fondos fotográficos públicos de manera consensuada es una asignatura pendiente en España. El hecho de que no contemos con centros de documentación específicos sobre la materia bajo control del Estado, ni tampoco con un museo nacional, es un claro ejemplo. El proyecto Infoco pretende precisamente la creación de un censo guía de fondos y colecciones fotográficos estatales en España, Portugal e Iberoamérica, con evidente vocación internacional y con el objetivo de dar a conocer los fondos invisibles y aquellos que siendo visibles se hallan dispersos en bibliotecas, archivos, institutos, fundaciones y otros centros. Se explican en este artículo los objetivos, la metodología y las actuaciones que se llevarán a cabo para conseguirlo.
\end{abstract}

Palabras clave: Documentación fotográfica. Fotografía. Infoco. Fondos y colecciones fotográficos. Gestión de colecciones. Recuperación de la información. España. Portugal. Iberoamérica.

\section{Introducción}

La necesidad de recuperación de la información es obvia; y, sin embargo, las iniciativas comunes para llevar a cabo tareas en lo que se refiere a la fotografía y, por extensión, a la documentación audiovisual han sido mínimas. Tal situación, unida a la dispersión de los fondos fotográficos en archivos, bibliotecas, museos, fundaciones, institutos y otros muchos centros de documentación, algunos insospechados, nos ha llevado a plantear una idea con el fin de hacer visible los fondos y colecciones fotográficos.

Una parte mínima de las instituciones de relevancia dependiente del estado, de las comunidades autonómas o de los ayuntamientos, ha mostrado interés por este tema, invirtiendo en

\begin{abstract}
The handling and management of the public photographic collections in a consensual manner is a matter still pending in Spain. The fact that no specific State-controlled documentation centers exist in this area, nor is there a national museum, is a clear example. The Infoco project is precisely intended to create a guide and census of the government's photographic collections in Spain, Portugal and Latin America, with a clear international orientation and with the idea of promoting the "invisible" collections and those which are visible, but are widely dispersed in libraries, archives, institutions, foundations and other centers. The goals, methodology and activities of this project are explained in this article, as well as the actions which should be taken in order to achieve this end.
\end{abstract}

Keywords: Photographic documentation. Photography. Infoco. Photographic collections. Collection management. Information retrieval. Portugal. Spain. Iberoamerica.

ello recursos humanos y técnicos; y aquellas entidades que lo han hecho no han mantenido contacto con otras similares, de forma que pueden accederse a los fondos sólo desde esa institución, por lo que es necesario de antemano conocer los contenidos o bien hacer la búsqueda a través de cada uno de ellos.

Nos encontramos así con dos problemas: el primero la visibilidad de los fondos, y el segundo la descoordinación entre centros similares en cuanto a su función y dependencia, que limita en consecuencia la tarea del investigador 0 interesado en las colecciones y sus temáticas.

Conviene hacer una mínima referencia a los valores de la fotografía como documento, y a los estudios que sobre ello se han llevan a cabo en la Universidad española, con referencias biblio- 
gráficas en recientes trabajos sobre patrimonio fotográfico (Sánchez Vigil, Olivera Zaldua, Salvador Benítez, 2013), o en clásicos sobre documentación (Valle, 1999; Boadas, 2001).

Cada instante se generan millones de fotografías cuya difusión es inmediata, bien en los medios de comunicación o bien en la red. Dichas imágenes contienen una información que puede o debe ser analizada, de gran interés en función de las necesidades de los investigadores, usuarios, receptores, etc. La fotografía es un mensaje sobre un soporte y por tanto un documento que permite, por su contenido, una lectura especial que depende de la mirada.

La fotografía es pública per se, y fue concebida para difundir, para dar a conocer, para mostrar. Sin embargo, esa característica se diluye por su invisibilidad en un momento en el que la tecnología permite la máxima difusión. El amplio espectro de la Documentación Fotográfica comprende los aspectos históricos, el análisis documental, el reconocimiento de materiales, la recuperación de la información, la gestión, los derechos de autor y de uso de las imágenes, la actividad profesional en centros públicos y privados, las colecciones, los fondos, bancos de imágenes y fototecas, el patrimonio, y naturalmente la investigación. Para que todo esto sea posible, es necesario en primer lugar hacer visibles los fondos y colecciones, analizando de manera general los contenidos para facilitar el acceso y por tanto la difusión.

\section{Origen de las colecciones fotográficas en España}

Los primeros estudios sobre patrimonio fotográfico en España se realizaron en Cataluña por Carles Vicent Guitart, quien recopiló en 1990 imágenes en 128 centros en su mayoría ubicados en Barcelona (Vicent, 1990). Posteriormente se realizó el Llibre Blanc del Patrimoni Fotogràfic (1994-1996), dirigido por Cristina Zelich y Josep Rigol, con el que se realizó el registro de diez millones de fotos de un centenar de instituciones, y cuyo objetivo fue conocer la situación del patrimonio. Ésta política se ha mantenido durante la primera década del siglo $\mathrm{XX}$ a través del Consell Nacional de la Cultura i les Arts de la Generalitat, que elaboró en 2011 un informe sobre la creación, conservación y difusión de la fotografía.

Otras comunidades han desarrollado también proyectos a través de instituciones, entre ellas el Centro de Historia de la Fotografía en la Región de Murcia, Centro de la Fotografía y la Imagen Histórica de Guadalajara, Fundación Universitaria de Navarra, Centro Andaluz de la Fotografía,
Centro Gallego de Artes de la Imagen, Centro de Documentación de la Imagen de Santander, el Departamento de Fotografía del Museo Nacional de Arte de Cataluña, o el Photomuseum de Zarautz, con cuatro congresos sobre historia de la fotografía y la preservación del patrimonio entre 2005 y 2009 . Tras una primera evaluación del estado de la cuestión observamos que existe una incalculable cantidad de originales en diversos soportes, una dispersión de los fondos y la necesidad de conservación y tratamiento del patrimonio.

En cuanto a las fuentes sobre la recuperación y tratamiento de fondos y colecciones hemos de hacer referencia al Censo-Guía de archivos y colecciones fotográficas de Álava realizado por Pilar Aróstegui (1988), el catálogo 150 años de fotografía en la Biblioteca Nacional. Guía inventario de los fondos de Gerardo Kurtz e Isabel Ortega (1989), la Guía de fons en imatge elaborada por Baodas y Casellas para el Ayuntamiento de Girona (1999), el citado Llibre blanc del patrimonio fotogràfic a Catalunya (1996), el Inventari d'Arxius de Albert Blanch (1998), la Guía d'arxius, col-leccions y fons fotogràfics $i$ cinematogràfics de les Balears, 1840-1967 de Catalina Aguiló y María Josep Mulet (2004), el inventario del Departament de Cultura i Mitjans de Comunicació de la Generalitat de Cataluña (2004), la Guía-Inventario de fondos y colecciones fotográficas de Canarias de Carmelo Vega, Isurkide, trabajo del Photomuseum de Zarautz para recopilar información sobre la fotografía en el País Vasco, y el estudio de Laia Foix (2011).

La necesidad del censo-guía de fondos y colecciones se justifica con la dispersión de los documentos, la cantidad y diversidad de los mismos, que hace urgente la elaboración de un censo-guía para profesionales e investigadores. Las grandes instituciones han realizado una tarea excepcional con el fin de difundir sus fondos (Biblioteca Nacional, Instituto del Patrimonio Cultural, Ministerio de Cultura, etc.), pero la gran mayoría permanecen todavía invisibles.

\section{Justificación y antecedentes}

El proyecto de elaborar un instrumento que censara los fondos y colecciones fotográficos estatales nace en septiembre de 2012, impulsado por el grupo de investigación Griweb de la Facultad de Ciencias de la Documentación de la UCM. El proyecto viene justificado por la ausencia de un organismo especializado de carácter público y ámbito nacional que coordine las actuaciones en materia de localización, recuperación, descripción y seguimiento de los fondos y colecciones fotográficos existentes en nuestro 
país, lo que ha hecho que una serie de instituciones públicas como los archivos, las bibliotecas y los museos, entre otros, se conviertan en centros receptores de documentación fotográfica, cuya función principal es la conservación de los materiales para la consulta de investigadores, estudiosos y de la sociedad en general. No obstante, este vacío se ha visto compensado por valiosas iniciativas.

En el ámbito de las bibliotecas, y en relación a España, es destacable la labor realizada en la Biblioteca Nacional de Madrid, con la publicación del trabajo 150 años de fotografía en la Biblioteca Nacional: Guía-inventario de los fondos fotográficos de la Biblioteca Nacional. En el campo de los archivos se debe mencionar el Censo-Guía de Archivos Españoles e Iberoamericanos elaborado por el Centro de Información Documental de Archivos (CIDA), dependiente del Ministerio de Cultura. Este instrumento de descripción proporciona información sobre los centros, depósitos y archivos incorporados en dicho censo (un total de 46.202), constituyendo una herramienta de difusión clave. Además, permite conocer la existencia de fotografías en las instituciones incluidas en dicho censo, constituyendo el primer paso para la conservación de los fondos fotográficos y su reconocimiento como parte del patrimonio documental del país.

La labor iniciada por este organismo ha impulsado a varias comunidades autónomas en la elaboración de inventarios, censos, guías y catálogos de los archivos de sus respectivos territorios, en los que se incluyen informaciones sobre la existencia de documentación fotográfica en los mismos. Destaca la labor desarrollada por el Ayuntamiento de Girona para la localización y recuperación de los fondos locales a través del Centre de Recerca i Difusió de la Imatge (CRDI).

Otra iniciativa de extraordinario valor es dFoto (http://www.dfoto.info), proyecto de la Universidad Politécnica de Valencia para la creación de un directorio de colecciones fotográficas (privadas y públicas). Es esta línea, el grupo Griweb de la Facultad de Ciencias de la Documentación de la Universidad Complutense de Madrid (UCM) estableció los contactos necesarios para trabajar conjuntamente, con respuesta positiva. Como resultado de las primeras conversaciones, Dfoto trabajaría en la recuperación de fondos locales, comunitarios y privados, mientras que el grupo Griweb mediante el proyecto Infoco se ocuparía de las colecciones estatales.

A pesar de todas estas iniciativas, aún no puede hablarse de la existencia de una guía del patrimonio fotográfico. Aunque en un primer momen- to el alcance del proyecto se limitó a instituciones españolas, posteriormente su objetivo se ha ampliado a otros países del ámbito hispano, concretamente Portugal e Iberoamérica, con la idea de contribuir también a la difusión y conservación de su patrimonio fotográfico.

\section{InFoCo (Instituciones con Fondos y Colecciones fotográficos): consideraciones}

Para plantear los objetivos y la metodología de trabajo, se llevó a cabo un estudio previo del estado de la cuestión, del que resultaron las siguientes consideraciones:

a) Ausencia de una relación exhaustiva de instituciones públicas de carácter estatal que posean fondos y colecciones fotográficas, tanto en España como en Portugal e Iberoamérica. En consecuencia, se parte de la hipótesis de que el volumen del patrimonio fotográfico público estatal es muchísimo más amplio cuantitativamente del que ya es conocido y está descrito.

b) Invisibilidad del Patrimonio, lo que imposibilita su cuantificación, su valoración cualitativa y, en consecuencia, su accesibilidad para los investigadores y estudiosos.

c) Inexistencia en España de un centro de documentación de carácter público y ámbito estatal especializado en documentación fotográfica que coordine las actuaciones en materia de localización, descripción y seguimiento de los fondos y colecciones fotográficas existentes en nuestro país. Dicha ausencia ha provocado que una serie de instituciones públicas como los archivos, las bibliotecas y los museos, entre otros, se conviertan en centros receptores de documentación fotográfica, cuya función principal es la conservación de los materiales para la consulta de investigadores, estudiosos y de la sociedad en general.

d) Falta de una estrategia adecuada de representación y difusión del patrimonio fotográfico. Los intentos parciales de difusión realizados hasta el momento, con algunas excepciones (Ministerio de Cultura), se basan en el propio material aportado, y en su incorporación a un repertorio digital por parte de los propios investigadores. Sin embargo, dado el volumen del material que aún debe darse a conocer, este modo de proceder centralizado (las mismas personas introducen la información en el sistema) haría excesivamente lenta y prolongada en el tiempo dicha labor de difusión, con el consiguiente peligro de duplicación de trabajos de investigación. Se parte de la hipótesis de que la estrategia más adecuada de representación y 
difusión consiste en que el personal de cada institución introduzca los datos en el sistema, proporcionándoles una contraseña de entrada.
De esta manera, los datos estarían constantemente al día y el proceso de difusión se realizaría en tiempo real.

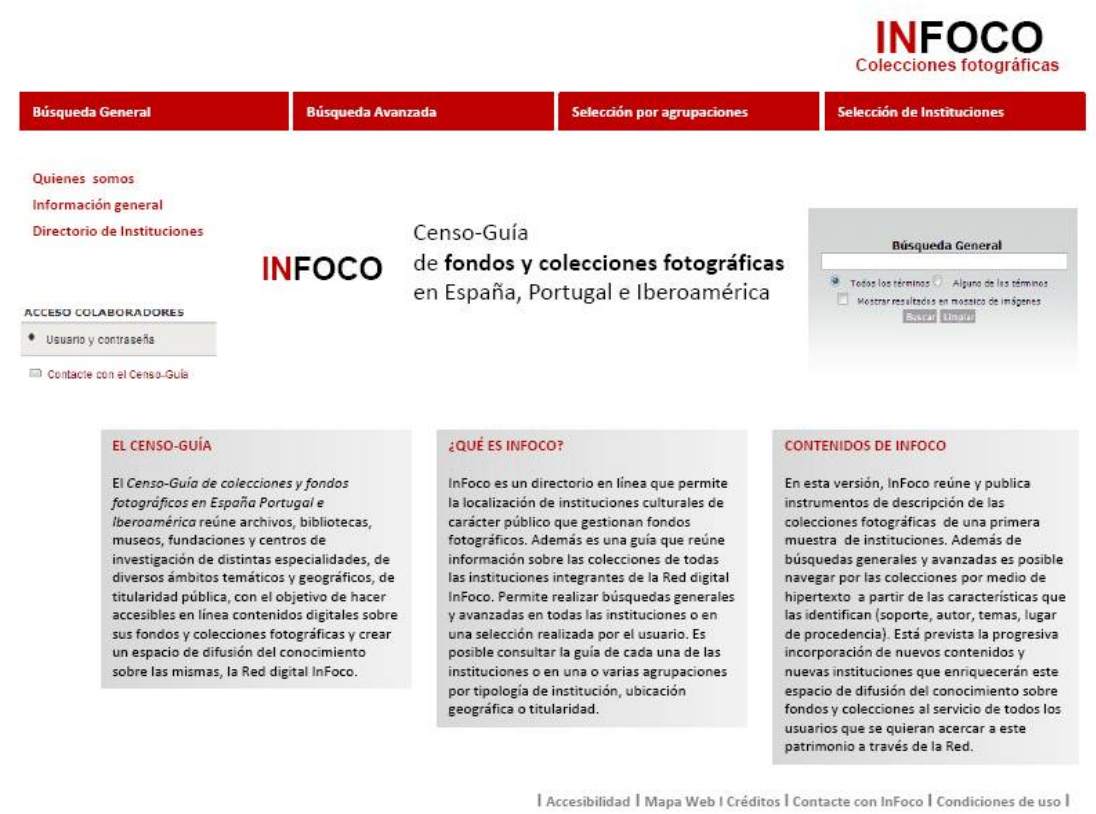

Figura 1. Boceto del portal Infoco, 2013

\section{Infoco: objetivos, metodología y actuaciones}

Dada la complejidad del proyecto en cuanto a la cantidad de posibles instituciones participantes y al número de fondos y colecciones que pueden formar parte de Infoco, se han establecido los objetivos generales y específicos, se ha diseñado una metodología que permita avanzar en la recuperación y al tiempo validar los resultados, y asimismo se han diseñado actuaciones en paralelo.

\subsection{Objetivos}

Se describen a continuación los objetivos generales y específicos, los primeros referidos a planteamientos globales y los segundos vinculados a las tareas.

\subsubsection{Objetivos generales}

a) Poner a disposición de la comunidad investigadora el patrimonio fotográfico dependiente del Estado español y las instituciones estatales de Portugal y los países iberoamericanos que se incorporen al proyecto, fundamentalmente México, Brasil, Argentina y Ecuador en una primera fase.

b) Establecer programas para el intercambio de experiencias y estudios en relación con la mate- ria y el tema planteado entre las comunidades científicas de España, Portugal e Iberoamérica.

c) Recuperación de toda la información relacionada con los fondos y colecciones fotográficas que se recojan en el desarrollo del proyecto.

d) Crear una herramienta para dicha recuperación y difusión. Asimismo, será herramienta de búsqueda de colecciones, fondos y materias.

e) Creación del Centro Estatal de Documentación Fotográfica, controlado por los responsables del proyecto, cuya función será la gestión de la información relacionada con las colecciones y fondos fotográficos dependientes de las instituciones públicas estatales españolas. De manera concreta, se encargará de responder a las cuestiones que planteen los investigadores sobre aspectos tales como: localización de los fondos, tipología de las colecciones y fondos, materias contenidas en ellos y modelos de gestión.

\subsubsection{Objetivos específicos}

a) Localizar los centros públicos estatales españoles con fondos y colecciones fotográficos.

b) Iniciar la localización de los centros públicos estatales con fondos y colecciones fotográficos en Portugal, Brasil, México, Argentina, Colombia y Ecuador. 
c) Elaborar una herramienta de descripción que recoja los principales datos sobre los fondos y colecciones fotográficos: ubicación física, volumen del fondo o colección, formatos de las fotografías, datos técnicos de las fotografías, datos sobre derechos de uso, reproducción o copia, y bibliografía con descripciones o estudios sobre dicho fondo o colección.

d) Desarrollar una base de datos que recopile todos estos datos.

e) Desarrollar un tesauro u ontología sobre aspectos temáticos involucrados en los fondos descritos.

f) Desarrollar un portal en Internet desde donde se difunda el contenido de la base de datos y todos aquellos que se consideren de interés para el cumplimiento de los objetivos.

g) Desarrollar un sistema de recuperación de información destinado a búsquedas sobre la información recopilada durante el proyecto, y a largo plazo el desarrollo de un sistema de recuperación de información especializado en material fotográfico.

h) Localización e identificación de fondos y colecciones fotográficos presentes en instituciones públicas de España, Portugal e Iberoamérica.

i) Elaboración de un censo de los fondos y colecciones fotográficos existentes, instrumento de control básico dirigido a la protección y defensa del patrimonio fotográfico en los países involucrados en el proyecto.

j) Creación de un directorio de los centros de gestión en España, Portugal e Iberoamérica, así como las colecciones fotográficas que custodian.

k) Desarrollo de una guía electrónica, instrumento de difusión a través de la web, para el conocimiento de los fondos y colecciones de fotografías existentes en instituciones públicas de España, Portugal e Iberoamérica por parte de la Administración, investigadores en la materia y los ciudadanos.

I) Publicación de los productos resultantes de la investigación.

m) Creación de un observatorio para el seguimiento y difusión de otros proyectos en materia de patrimonio fotográfico de naturaleza pública o privada.

\subsection{Metodología}

Para desarrollar el proyecto se llevarán a cabo las siguientes actividades, de acuerdo a la cro- nología que se diseñe en función de la temporalidad.

a) Localización e identificación de instituciones públicas gestoras de colecciones de fotografías, a través de:

- Estudio bibliográfico de atálogos, guías, instrumentos de descripción e investigaciones publicadas sobre fondos y colecciones fotográficas en España, Portugal e Iberoamérica.

- Consultas y entrevistas con investigadores especializados en la materia.

- Censo-Guía de Archivos de España e Iberoamérica (CIDA-Ministerio de Cultura, España).

b) Mapeo de los fondos, colecciones fotográficas y centros de custodia localizados

- Diseño e implementación de un portal web del Censo-Guía como plataforma de trabajo y comunicación con las instituciones y países participantes, así como centro de difusión de los objetivos, alcance y fases de desarrollo del proyecto.

c) Recogida de datos y descripción de los conjuntos documentales

- Diseño de una herramienta online para la recogida de datos correspondientes a los fondos y colecciones fotográficas. La cumplimentación y carga de datos en el formulario se hará directamente por los centros informantes.

d) Difusión y consulta web

- Portal del Censo-Guía que dé acceso a:

- Directorio de instituciones (por países).

—Directorio de colecciones.

- Guía de los conjuntos fotográficos, que proporcione información sobre el volumen, soportes, autores, fechas y temas de la documentación.

- Inventario dinámico que permita navegar por la estructura de los conjuntos documentales (fondo, serie, colección, unidad documental, etc.).

- Mapa sensible con geolocalización de las instituciones gestoras de las colecciones fotográficas.

e) Observatorio

- Seguimiento de proyectos, iniciativas y publicaciones en materia de patrimonio fotográfico. 
- Difusión de estas iniciativas en el portal del Censo-Guía.

\subsection{Actuaciones}

Las actuaciones se llevarán a cabo en función del cronograma, desarrollando tareas generales por todo el equipo o especificas por cada uno de los miembros. Las primeras actuaciones serán de presentación del proyecto con el fin de darlo a conocer a la comunidad científica, despertar su interés y conocer el valor del mismo en relación a los intereses.

La difusión se realizará en eventos de prestigio, nacionales e internacionales organizados por instituciones públicas de relevancia, tales como los congresos Fesabid, Ibersid o Coloquio Iberoamericano, así como en Seminarios internacionales de carácter universitarios, tales con los Seminarios Hispano-Mexicano e Hispano-Brasileño, ambos organizados por departamentos y facultades de la Universidad Complutense, la Universidad Autónoma de México o la Universidad de Brasilia. Por otra parte se desarrollarán actividades específicas en Jornadas de referencia como las Jornadas de Fotografía y Documentación Fotodoc.

Un segundo y no menos importante aspecto de las primeras actuaciones es la identificación de centros con interés en incluir sus colecciones en Infoco, así como el acuerdo con profesores de universidades de los países implicados que se responsabilicen de la gestión en cada país.

\section{Conclusiones}

Analizado el estado de la cuestión, vistas las posibilidades de recuperación de colecciones invisibles, valorado el interés de participación de numerosas instituciones y trazado el programa de actuación de acuerdo a los objetivos, señalamos cinco conclusiones principales:

- La dispersión de los fondos y colecciones en los centros públicos es un hecho. En consecuencia el desconocimiento de los mismos impide su estudio y la obtención de beneficios tras la investigación.

- Es imprescindible la creación de un organismo, entidad o centro que se encargue de la recuperación de dichos fondos y colecciones con el fin de hacerlos visibles, generando los medios necesarios para ello.

- El intercambio de información entre los países iberoamericanos que formen parte del proyecto contribuirá a difundir la cultura, a la interrelación global y a fomentar la investiga- ción sobre temas o materias específicos resultantes del vaciado de las colecciones $y$ fondos.

- La creación de un portal permitirá la difusión de otro tipo de actividades de las instituciones implicadas, y obviamente la realización de encuentros periódicos que permitirán el desarrollo del proyecto.

\section{Referencias}

Aguiló, Catalina; Mulet, Maria-Josep (2004). Guía d’arxius, col.leccions i fons fotogràfics i cinematrogràfics de les Balears, 1840-1967. Palma: Fundacion Sa Nostra.

Alonso Laza, Manuela (2007): La dimensión social y cultural de los archivos de imágenes: la experiencia del Centro de Documentación de la Imagen de Santander (CDIS). // Arxius d'Imatges, Revista d' Arxius. 6, 51-68.

Blanch, Albert (1998). Arxius Fotográfics de Catalunya. Barcelona, Azimut.

Boadas, J.; Casellas, LI. E.; Suquet, M. Angels (2001). Manual para la gestión de fondos y colecciones fotográficas. Girona: Curbet Comunicació Gràfica.

Doñemo Martínez de Morentín, Asunción (2005). La gestión del fondo fotográfico de la universidad de Navarra: custodia, difusión y función académica. // Actas de las jornadas ¡Qué hacemos con la fotografía de archivo?, 7 y 8 febrero. http://archivo.ayuncordoba.es/Agenda.htm (9 de julio de 2011).

Foix, Laia (2011). Patrimonio fotográfico de Catalunya en la red. // El profesional de la información. 20:4, 378-383.

Freixa Font, Pere (2011). Patrimonio fotográfico y web 2.0: la experiencia Flickr de Commons. // El profesional de la información. 20:4, 432-438.

Gato-Gutiérrez, Mario; et al. (2011). Colecciones de fotografía en España: Propuesta del Directorio Fotográfico en España (dFoto). // Imatge i Recerca. 11es Jornades Antoni Varés. Girona, Ayuntamient. 137-139.

Letón Ruiz, Raquel; Martín Rizaldos, Silvia; Martín García, Leticia (2008). Pautas y actuaciones para la gestión integral de fondos y colecciones fotográficas, en Imatge i Recerca. 10 Jornades Antoni Varés. Girona: Ayuntamiento. 95-97. http://www.ajuntament.gi/sgdap/cat/jorna des_actes.php.

Riego et al, Bernardo (1997). Manual para el uso de archivos fotográficos. Madrid: Ministerio de Cultura.

Robledano Arillo, Jesús; Moreiro González, José Antonio (2002). La recuperación documental de la imagen fotográfica: perspectiva tecnológica y documental. Madrid: Archiviana.

Sánchez Vigil, Juan Miguel (2006). El documento fotográfico: historia, usos y aplicaciones. Gijón: Trea.

Sánchez Vigil, Juan Miguel; Olivera Zaldua, María; Salvador Benítez, Antonia (2013). Patrimonio fotográfico. Madrid: Síntesis. 177-214.

Valle Gastaminza, Félix (editor, 1999). Manual de documentación fotográfica. Madrid: Síntesis.

Vicent i Guitar, Carles (1990). Els arxius d’imatges a Catalunya: balanc I perspectives, en La Imatge i la Recerca Històrica. Girona, Ayuntamiento. 9-25.

Enviado: 2013-05-28. Segunda versión: 2013-08-25 Aceptado: 2013-08-27. 